The Cryosphere, 4, 179-190, 2010

www.the-cryosphere.net/4/179/2010/

doi: $10.5194 /$ tc-4-179-2010

(c) Author(s) 2010. CC Attribution 3.0 License.

\title{
Modelling snowdrift sublimation on an Antarctic ice shelf
}

\author{
J. T. M. Lenaerts ${ }^{1}$, M. R. van den Broeke ${ }^{1}$, S. J. Déry ${ }^{2}$, G. König-Langlo ${ }^{3}$, J. Ettema ${ }^{1}$, and P. K. Munneke ${ }^{1}$ \\ ${ }^{1}$ Institute for Marine and Atmospheric research Utrecht, Utrecht University, Utrecht, The Netherlands \\ ${ }^{2}$ University of Northern British Columbia, Prince George, Canada \\ ${ }^{3}$ Alfred Wegener Institüt für Polar- und Meeresforschung, Bremerhaven, Germany
}

Received: 23 December 2009 - Published in The Cryosphere Discuss.: 9 February 2010

Revised: 20 April 2010 - Accepted: 2 May 2010 - Published: 10 May 2010

\begin{abstract}
In this paper, we estimate the contribution of snowdrift sublimation $\left(\mathrm{SU}_{\mathrm{ds}}\right)$ to the surface mass balance at Neumayer, located on the Ekström ice shelf in Eastern Antarctica. A single column version of the RACMO2-ANT model is used as a physical interpolation tool of high-quality radiosonde and surface measurements for a $15-\mathrm{yr}$ period (1993-2007), and combined with a routine to calculate snowdrift sublimation and horizontal snow transport. The site is characterised by a relatively mild, wet and windy climate, so snowdrift is a common phenomenon. The modelled timing and frequency of snowdrift events compares well with observations. This is further illustrated by an additional simulation for Kohnen base, where the timing of snowdrift is realistic, although the modelled horizontal transport is overestimated. Snowdrift sublimation is mainly dependent on wind speed, but also on relative humidity and temperature. During high wind speeds, $\mathrm{SU}_{\mathrm{ds}}$ saturates and cools the air, limiting its own strength. We estimate that $\mathrm{SU}_{\mathrm{ds}}$ removes around $16 \% \pm 8 \%$ of the accumulated snow from the surface. The total sublimation more than triples when snowdrift is considered, although snowdrift sublimation limits sublimation at the surface. $\mathrm{SU}_{\mathrm{ds}}$ shows a strong seasonal cycle, as well as large inter-annual variability. This variability can be related to the variability of the atmospheric conditions in the surface layer.
\end{abstract}

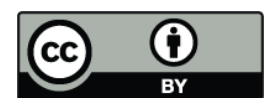

Correspondence to: J. T. M. Lenaerts (j.lenaerts@uu.nl)

\section{Introduction}

The surface mass balance (SMB), together with the flow of ice, determines the net mass change of the Antarctic ice sheet and the corresponding sea-level change (Vaughan et al., 1999; Rignot et al., 2008). The specific SMB of a snow/ice surface ( $\mathrm{mm} \mathrm{yr}^{-1}$, Van de Berg et al., 2006) can be written as the annual sum of precipitation (P), sublimation at the surface $(\mathrm{SU})$, runoff $(\mathrm{RU})$ and erosion $\left(\nabla \cdot \mathrm{TR}_{\mathrm{ds}}\right)$ and sublimation $\left(\mathrm{SU}_{\mathrm{ds}}\right)$ of drifting snow:

$\mathrm{SMB}=\int_{\text {year }}\left(\mathrm{P}-\mathrm{SU}-\mathrm{RU}-\nabla \cdot \mathrm{TR}_{\mathrm{ds}}-\mathrm{SU}_{\mathrm{ds}}\right) d t$

Figure 1 shows that the modelled SMB varies strongly on the Antarctic continent. The high inland plateau is dry (SMB below $70 \mathrm{~mm} \mathrm{yr}^{-1}$ ), whereas in the coastal regions the SMB is much larger, especially in the Antarctic Peninsula (Turner et al., 2002).

A considerable effort has been made to determine the accumulation (precipitation minus sublimation, $\mathrm{P}-\mathrm{SU}$ ) in Antarctica (e.g., Giovinetto et al., 1992; Van de Berg et al., 2006). The contribution of $\mathrm{SU}_{\mathrm{ds}}$ to the $\mathrm{SMB}$, however, is largely unknown because direct measurements are unavailable (Pomeroy and Essery, 1999). Although assumed important on a local scale, earlier studies considered snowdrift sublimation to be a negligible term in the continent-wide surface mass budget (e.g., Turner et al., 1999). Different modelling studies, however, demonstrated that sublimation due to snowdrift equals surface sublimation (King et al., 1996; Mann et al., 2000) or even exceeds surface sublimation at coastal and katabatic wind-controlled Antarctic sites (Bintanja, 2001a; Bintanja and Reijmer, 2001; Frezzotti et al., 2004). On a continental scale, estimates indicate a removal of

Published by Copernicus Publications on behalf of the European Geosciences Union. 

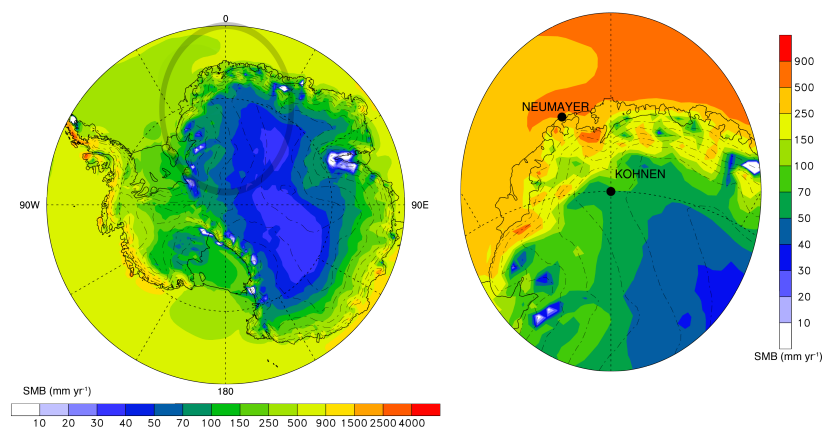

Fig. 1. The SMB distribution (from RACMO2/ANT for the period 1958-2002, Van de Berg et al., 2005) on the whole Antarctic continent (left) and zoomed in on the region between $20^{\circ} \mathrm{E}$ and $20^{\circ} \mathrm{W}$, as indicated with the circle in the left plot. Note the different scale on both plots. The locations of Neumayer and Kohnen stations are indicated on the right plot. The distance between both stations is about $550 \mathrm{~km}$. The topography is shown in both plots by the dashed height contours (500 $\mathrm{m}$ resolution).

$10-50 \%$ of snowfall in the North American (seasonal) snowcovered regions (Pomeroy and Essery, 1999), 5\% in Greenland (Box et al., 2006) and around 15-20\% in Antarctica (Bintanja, 1998), although the latter may be overestimated.

The snowdrift layer can extend several hundreds of metres above the surface (Budd, 1966) and affects vertical profiles of wind, temperature and humidity in the atmospheric boundary layer (Déry et al., 1998; Bintanja, 2000). Most regional climate models lack horizontal and vertical resolution to fully capture this process. This negatively affects the representation of the SMB by these models. Schlosser (1999) concluded that the limited agreement between her atmospheric model and observations on the accumulation rates at Neumayer (Fig. 1) could be related to the absence of representation of the snowdrift physics in the model. Moreover, most models neglect the negative feedback between $\mathrm{SU}_{\mathrm{ds}}$ and the thermodynamic conditions of the atmosphere and the resulting self-limiting behaviour of $\mathrm{SU}_{\mathrm{ds}}$ (Bintanja, 2001b; Déry and Yau, 2002; Mann et al., 2000). This may result in a significant error in the $\mathrm{SU}_{\mathrm{ds}}$ estimates (Déry et al., 1998). The purpose of this paper is to estimate as realistically as possible the contribution of $\mathrm{SU}_{\mathrm{ds}}$ to the $\mathrm{SMB}$ at Neumayer station, which is situated on the Ekström ice shelf in coastal East Antarctica (Fig. 1). Neumayer has a relatively mild and windy climate with frequent snowfalls, and snowdrift is a common occurrence at this location. Assuming runoff due to melt and snowdrift erosion to be negligible, we can also provide an estimate of precipitation at Neumayer.

We use the updated single column version (SCM) of the coupled land-atmosphere ECMWF model. To simulate snowdrift sublimation at Neumayer, it contains the same physical parameterizations as RACMO2/ANT, which has proven to realistically simulate Antarctic climate conditions (Van de Berg et al., 2005). The model is driven by high-quality observations, ensuring that the interactions between $\mathrm{SU}_{\mathrm{ds}}$ and atmosphere and surface roughness are considered. The seasonal as well as the inter-annual variability of $\mathrm{SU}_{\mathrm{ds}}$ are discussed. Another simulation is performed for a station on the Antarctic plateau (Kohnen base, Fig. 1) to highlight the importance of the meteorological conditions on the snowdrift sublimation process at these different locations.

\section{Methods}

\subsection{Snowdrift model}

In order to calculate the horizontal transport of snow $\left(\mathrm{TR}_{\mathrm{ds}}\right)$ in models and from observations, several authors have developed a simple relation between friction velocity $u_{*}$ and snowdrift flux, using a threshold wind speed for snowdrift (e.g., Mann et al., 2000; Déry and Yau, 2002). Snowdrift sublimation, however, is usually not considered in atmospheric models. The physics of this process is complex because of the many interactions and feedbacks: snowdrift exerts friction on the flow and cools and moistens the surface layer, in turn limiting snowdrift and surface sublimation. Existing models that include $\mathrm{SU}_{\mathrm{ds}}$ are based on similar physical concepts (Xiao et al., 2000). Due to the high vertical resolution and many snow grain size classes $(\geq 50)$ required to resolve the size particle spectrum, these models are computationally very expensive. Therefore, Déry and Yau (1999) developed a simplified bulk version of one of these models. In this routine, a new variable, the mixing ratio of blowing snow $q_{b}\left(\mathrm{~kg} \mathrm{~kg}^{-1}\right)$ is introduced, which is related to the spectral number density. Moreover, a prognostic equation for blowing snow particle numbers is defined in the model (Déry and Yau, 2001). In addition to $q_{b}$, temperature and humidity are also calculated prognostically on a vertical grid (24 levels), to ensure conservation of heat and moisture in the snowdrift layer. The competing processes of turbulent diffusion, settling and sublimation influence the snowdrift variables, whereas only turbulent diffusion and sublimation affect the thermodynamic variables. Based on the simulated profiles of snowdrift, the model provides estimates of the column-integrated rates of horizontal snowdrift transport $\mathrm{TR}_{\mathrm{ds}}\left(\mathrm{kg} \mathrm{m}^{-1} \mathrm{~s}^{-1}\right)$ and sublimation $\mathrm{SU}_{\mathrm{ds}}\left(\mathrm{mm} \mathrm{d}^{-1}\right.$ water equivalent or we). Although the bulk method is simplified compared to the spectral method, tests indicated that the bulk model matches very well with its spectral variant, simulating similar thermodynamic tendencies and sublimation rates (Déry and Yau, 1999; Xiao et al., 2000). In the SCM, the bulk snowdrift model is driven by near-surface temperature, relative humidity with respect to ice $\left(\mathrm{RH}_{i}\right)$, wind speed and surface pressure at each time step.

The snowdrift routine in the model is limited in the vertical dimension from $0.1 \mathrm{~m}$ to $100 \mathrm{~m}$ height. The snowdrift routine is activated when the friction velocity $u_{*}$ exceeds a threshold value $u_{*, t}$, here set to $0.3 \mathrm{~m} \mathrm{~s}^{-1}$, and if the temperature is below freezing. $u_{*, t}$ depends on snow surface 
characteristics. Snowdrift is suppressed when the surface snow is more consolidated. In this respect, the density of snow can be a suitable parameter to define the onset of snowdrift (Gallée et al., 2001). Moreover, snowdrift increases the friction velocity, reducing near-surface wind speed (Bintanja and Reijmer, 2001). Because we force the model with observed wind speed, this effect is implicitly considered in this study. Moreover, fresh snow is accumulated frequently at Neumayer, implying that the consolidation of snow is limited and the surface snow density is rather constant with time. We, therefore, kept $u_{*, t}$ constant.

\subsection{Atmospheric and snow model}

For this study, the single column version of the updated coupled land-atmosphere ECMWF model (cycle C23YR; White, 2001) is used and referred to as RACMO2/SCM. Physical parameterizations are adapted to realistically simulate the Antarctic climate conditions, similar to the RACMO2/ANT model (Van de Berg et al., 2005). Moreover, the model has been expanded with a snow model, calculating density, temperature and liquid water in the snow (Ettema et al., 2009). A single grid cell ("column") is defined, in which only vertical exchange can occur between 60 vertical levels. Fourteen of these are situated in the lowest $2 \mathrm{~km}$ of the atmosphere, to obtain a realistic representation of the boundary layer. The lowest model level is located around $7 \mathrm{~m}$ above the surface. A time step of $15 \mathrm{~min}$ is used, which is sufficient to resolve the interactions between the surface conditions and $\mathrm{SU}_{\mathrm{ds}}$.

For the purpose of this study, it is vital that the model represents the atmospheric conditions realistically, especially near the surface. Therefore, we created a continuous dataset of boundary conditions from available radiosondes and mast measurements of a period of 15 consecutive years (19932007). In essence, this means that the SCM is used as a physical interpolator of the forcing data. These data are used directly by the SCM to calculate the prognostic variables at each model time step.

At Neumayer, radiosondes are released every $24 \mathrm{~h}$, sometimes every $12 \mathrm{~h}$. The vertical distance between two adjacent measurement points varies between 25 to $100 \mathrm{~m}$ throughout the profile, with a median value of around $40 \mathrm{~m}$ in the lower troposphere. Measured variables are temperature, relative humidity (converted to dew-point temperature), wind speed and direction and pressure. Relative humidity is measured with respect to water, which we have converted to relative humidity with respect to ice $\left(\mathrm{RH}_{i}\right)$ according to Hyland and Wexler (1984) and rescaled using a technique described by Anderson (1994). We linearly interpolated the radiosonde data to a regular time grid of $12 \mathrm{~h}$, which is used to force the SCM. Next, linear interpolation is also used to convert the observations to model levels. Because of occasional erroneous and incomplete radiosonde data near the surface, we replaced the near-surface radiosonde data by mast measurements of $2 \mathrm{~m}$ temperature, $2 \mathrm{~m} \mathrm{RH} i$ and $10 \mathrm{~m}$ wind speed.
Table 1. Overview of geographical and land surface parameters at Neumayer in RACMO2/SCM.

\begin{tabular}{lll}
\hline Parameter & Value & Unit \\
\hline Altitude & 42 & $\mathrm{~m}$ a.s.l. \\
Latitude & 70.65 & ${ }^{\circ} \mathrm{S}$ \\
Longitude & 8.25 & ${ }^{\circ} \mathrm{W}$ \\
Albedo & 0.85 & - \\
Roughness length & 0.00025 & $\mathrm{~m}$ \\
Surface snow density & 400 & $\mathrm{~kg} \mathrm{~m}^{-3}$ \\
Initial snow temperature & 268.15 & $\mathrm{~K}$ \\
\hline
\end{tabular}

This implies that the lowest two model levels (around 7 and $18 \mathrm{~m}$ ) partly obtain values which are linearly interpolated between the mast measurement and the first atmospheric measurement of the radiosonde $( \pm 40 \mathrm{~m})$. Wind speed at the lowest level is equal to the $10 \mathrm{~m}$ wind times 0.76 , so that the resulting annual mean $10 \mathrm{~m}$ wind speed in the model equals the mean observed $10 \mathrm{~m}$ wind speed. As a final step, the $\mathrm{RH}_{i}$ values are converted to specific humidity. This is done in the final stage, because the calculation of snowdrift sublimation is directly dependent on the RH input; interpolating specific instead of relative humidity would decrease the accuracy of the $\mathrm{RH}$ input values.

Apart from the vertical profiles, land surface parameters are adapted in order to simulate surface characteristics at Neumayer (Table 1). The albedo is assumed to be constant in time $(0.85)$ to ensure a realistic shortwave energy balance. The roughness length for momentum is set to $0.25 \mathrm{~mm}$ (typical for ice shelf surfaces during strong snowdrift, see König, 1985), while the roughness length for heat is calculated using the scalar roughness length formulation given by Andreas (1987). Including a dependency of roughness length to friction velocity (following Bintanja and Reijmer, 2001) did not significantly change the results. For a 1-year simulation (1997) the average $z_{0}$ value increased from $0.25 \mathrm{~mm}$ to $0.34 \mathrm{~mm}$ and the snowdrift sublimation decreased by $2 \mathrm{~mm}$, which is only $1.5 \%$ of the original value. Surface pressure is available from mast measurements.

The measurement site (Kohnen, $75^{\circ} \mathrm{S}-0^{\circ} \mathrm{W}$ ) is located on the Antarctic Plateau at a height of $2893 \mathrm{~m}$ above sea level (Fig. 1). The location is characterised by low temperatures and little precipitation. For Kohnen, the data is collected in an identical manner and the above adaptations of the landsurface parameters are used.

\subsection{Implementation}

In practice, snow particles suspended in the flow will exhibit mass loss due to sublimation, thereby adding moisture to and extracting heat from the surrounding air. The snowdrift routine is implemented in the turbulent diffusion scheme of RACMO2/SCM (Fig. 2), which solves the energy balance 


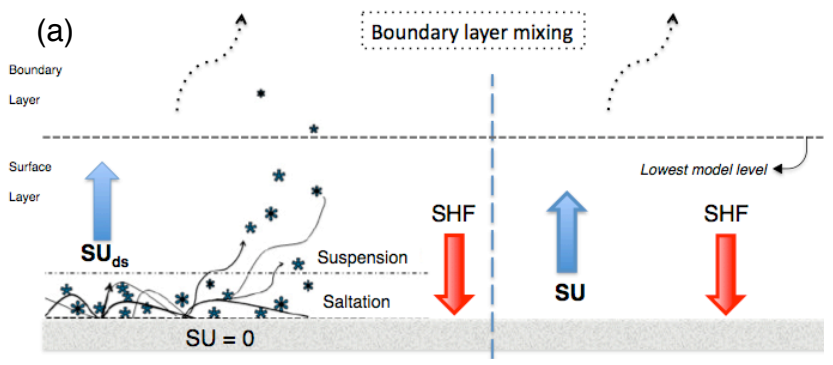

(b)

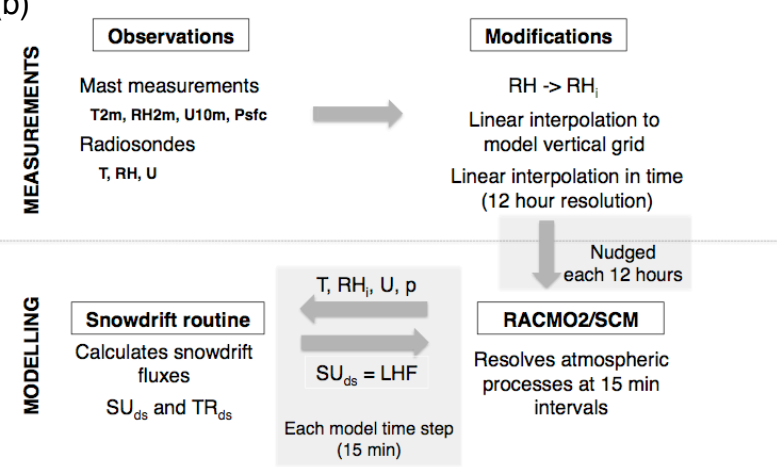

Fig. 2. (a) Schematic illustration of the snowdrift sublimation process in RACMO2/SCM. The left side represents the situation when snowdrift is activated, the right side when snowdrift is not active. The horizontal dashed line marks the boundary between the surface layer and the boundary layer in the model, which is the lowest model level $(7 \mathrm{~m})$. (b) Flow chart of the methods and tools used in this paper.

between the surface and the lowest model level (around $7 \mathrm{~m}$ height). In reality, of course, the exchange of energy occurs above the snowdrift layer. Déry and Yau (1999) show that $\mathrm{SU}_{\mathrm{ds}}$ strength decays exponentially with height, so the largest amounts of $\mathrm{SU}_{\mathrm{ds}}$ occur in the lowest metres above the surface. In case of a modelled friction velocity exceeding a certain threshold value (see above), the snowdrift scheme is activated (left panel).

Firstly, the necessary prognostic variables from RACMO2/SCM (RH, T, $U$ ) at the lowest model level are supplied to the snowdrift routine. Secondly, the resulting integrated sublimation rate is converted to the latent heat flux, which is then prescribed in the turbulent diffusion scheme. The sensible heat flux formulation remains unchanged. Finally, the turbulent diffusion scheme converges towards a solution for the surface temperature given this forcing. In reality, sublimation cools the surface of the snow particles, setting up a temperature gradient between the snow particles and the air. This in turn sets up a sensible heat ux from the air to the snow particles, cooling the air and keeping the snow particles in approximate thermal equilibrium with their surroundings. In the model, this cooling effect of snowdrift sublimation is simulated as follows: the heat needed for snowdrift sublimation is prescribed to be extracted from the model snow surface. As a result, the skin temperature in the model decreases, the temperature gradient between the air and the surface increases, enhancing the downward sensible heat ux, heating the surface and cooling the near- surface air. Surface temperature and humidity will thus adapt to the release of latent energy related to $\mathrm{SU}_{\mathrm{ds}}$. The additional moisture will also be brought into the boundary layer by turbulent mixing. This feedback is implicitly included in this experiment, because atmospheric conditions are prescribed to the model. These observations and, thus, the model, implicitly incorporate these cooling and saturating effects. The model should be regarded as a physical interpolation tool in time and height and to calculate surface energy exchange that is consistent with the conditions in the atmospheric boundary layer and in the snowpack.

We performed a simulation with (referred to as DRIFT) and without (hereafter NODRIFT) using the snowdrift routine.

\section{Meteorological conditions at Neumayer}

Neumayer is situated near the East Antarctic coast on the Ekström Ice Shelf. This site is situated close to the circumpolar trough of low pressure, the climatological expression of synoptic disturbances moving eastward around Antarctica. Neumayer is situated south of this trough and experiences low surface pressure values and relatively strong easterly winds. Figure 3 shows the profiles of temperature, specific humidity and wind speed which are used as input for RACMO2/SCM at Neumayer. We focus on one particular year (1997), as its anomaly of the near-surface observations with the respect to the mean is small, to show the typical intra-annual variability. The largest seasonal cycle is found in the lower atmosphere. The $2 \mathrm{~m}$ temperature is around $270 \mathrm{~K}$ in summer and around $240 \mathrm{~K}$ in winter; the annual mean equals $257 \mathrm{~K}$. Specific humidity values of $3 \mathrm{~g} \mathrm{~kg}^{-1}$ can be found frequently in summer throughout the boundary layer, whereas in winter values are an order of magnitude lower. Zonal wind speed is larger in winter, with frequent strong easterly winds (more than $20 \mathrm{~m} \mathrm{~s}^{-1}$ ) in the lowest $2 \mathrm{~km}$ connected with storm systems moving eastward. The meridional wind is significantly weaker. Relative humidity near the surface is lower in summer than in winter. In wintertime, the surface layer is mostly near or at saturation, connected with high winds, generating snowdrift and low temperatures. The annual mean $2 \mathrm{~m} \mathrm{RH}_{i}$ is $91 \%$. More details on the climate of Neumayer can be found in König-Langlo et al. (1998) and König-Langlo and Loose (2007).

Figure 4 shows the modelled mean summer, winter and annual vertical profiles of the above variables for the lowermost $5 \mathrm{~km}$ of the atmosphere. The strong stable stratification of the lower atmosphere is clearly visible in the potential temperature profiles. The potential temperature at the surface 

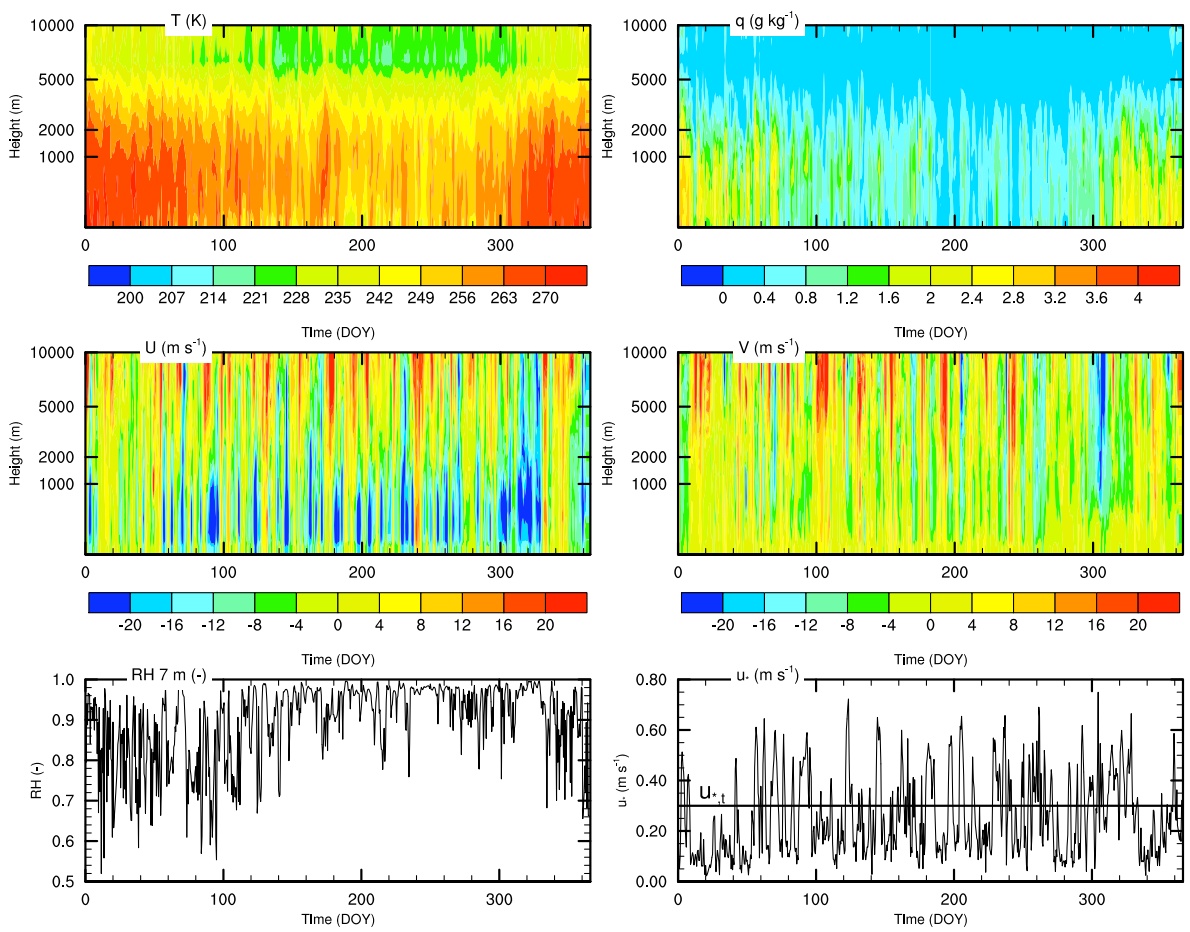

Fig. 3. Time-height sections of temperature $(T)$, specific humidity $(q)$ and wind speed components $(U$ and $V)$ from available radiosonde data and mast measurements at Neumayer, year 1997. The height coordinates are shown according to the vertical resolution in the model, i.e. higher resolution towards the surface. The lowest plot shows the time evolution of $\mathrm{RH}_{i}$ at the lowest model level ( $\left.7 \mathrm{~m}\right)$ and the friction velocity $u_{*}$, together with $u_{*, t}$ (horizontal line).

is about $6 \mathrm{~K}$ lower than at $200 \mathrm{~m}$ height, while $\mathrm{RH}_{i}$ is about $20 \%$ higher. Zonal flow dominates; the meridional flow is restricted to the lower atmosphere and is strongly reduced near the surface due to friction. This plot also confirms that winter wind speeds are significantly larger than in summer, especially the zonal component, by about $2 \mathrm{~m} \mathrm{~s}^{-1}$. The wind speed maximum in $U$ is caused by thermal wind effects, forcing near-surface easterlies to change in upper-atmosphere westerlies. Neumayer is situated in a region with strong horizontal meridional temperature gradients, which explains the strong east-to-west turning of the zonal flow (Van den Broeke et al., 2002b, 2003).

Figure 5 gives the seasonal cycle of the modelled mean energy balance components using observations, without snowdrift allowed (Van den Broeke et al., 2010). The annual mean net shortwave energy flux is positive $\left(19 \mathrm{~W} \mathrm{~m}^{-2}\right)$, whereas the longwave energy balance is strongly negative $\left(-30 \mathrm{~W} \mathrm{~m}^{-2}\right)$. The sum of the radiative fluxes is clearly negative in winter, due to the absence of incoming solar radiation and only positive from November to January. The shortage of solar energy is compensated by a positive sensible heat flux in winter (13 $\mathrm{W} \mathrm{m}^{-2}$ annual mean). The latent heat flux is slightly positive in winter and negative in summer due to sublimation. The annual mean LHF is $-2 \mathrm{~W} \mathrm{~m}^{-2}$. The ground heat flux is small and positive in winter and negative in summer. Melt occurs only in December and January and is small compared to the other surface fluxes.

\section{Snowdrift climate}

\subsection{Effects of interpolation}

Snowdrift sublimation is greatly influenced by the nearsurface atmospheric conditions (Déry and Yau, 2002). The model is forced by observations every $12 \mathrm{~h}$. To examine the effects of temporal and spatial interpolation on the conditions near the surface, key modelled and observed variables are shown in Fig. 6, again for the year 1997. The interpolated near-surface temperature, wind and relative humidity match well with hourly observations. The input at the lowest levels comes from hourly mast measurements, and the surface energy balance is calculated in the model, which ensures that the daily cycle is well represented. Small scatter is seen in temperature $\left(R^{2}=0.94\right)$ but is somewhat larger in wind $\left(R^{2}=0.87\right)$ and relative humidity $\left(R^{2}=0.88\right)$. Model wind and RH depart from observations in some cases, because observed rapid fluctuations within $12 \mathrm{~h}$ are not captured by the model. In general, however, model wind speed compares very well with observations and the model simulates a similar timing and frequency of the snowdrift events 

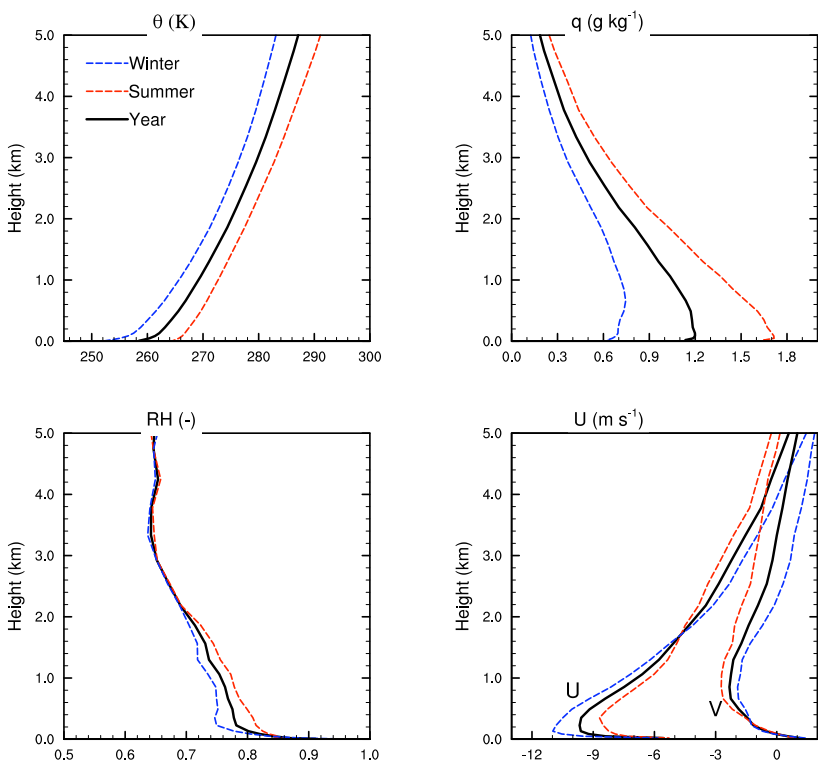

Fig. 4. Average vertical profiles in the lower atmosphere of potential temperature $(\theta)$, specific $(q)$ and relative humidity $(\mathrm{RH})$ and wind speed components ( $U$ and $V$ ) of summer (January-March and October-December), winter (April-October) and year 1997, simulated by RACMO2/SCM.

(Fig. 7b). Snowdrift occurs around $40 \%$ of the time in the model, which is a slight overestimation compared to the 3-h observations (33\%). These snowdrift observations are "synops", i.e. measurements performed at Neumayer according to WMO standards (König-Langlo and Loose, 2007).

Despite the good agreement between interpolated model values and observations, it is important to check whether the outliers in wind and relative humidity would greatly affect the simulated $\mathrm{SU}_{\mathrm{ds}}$. To examine this, we forced a simple parameterization for $\mathrm{SU}_{\mathrm{ds}}$, derived by Déry and Yau (2001), with hourly observations and with hourly model variables (Fig. 7a). This parameterization is defined as an empirically derived function of near-surface temperature, $\mathrm{RH}_{i}$ and wind speed (Déry and Yau, 2001). The agreement is good, yielding a cumulative amount of around $90 \mathrm{~mm}$ in the year 1997 (Fig. 7a). This confirms that the effect of the spatial and temporal interpolation is small. Note that this simple parameterization overestimates $\mathrm{SU}_{\mathrm{ds}}$ by around $25 \%$ compared to the bulk snowdrift model used in this study.

The surface energy balance is altered by snowdrift sublimation, because latent heat is extracted from the air in the surface layer (Fig. 7b). During events of snowdrift, the magnitude of the latent heat flux becomes as large as $90 \mathrm{~W} \mathrm{~m}^{-2}$, while surface sublimation ceases. When snowdrift occurs (see markers), the latent heat release due to snowdrift sublimation (green line) is mostly larger than the latent heat loss connected to surface sublimation (red line). This suggests that $\mathrm{SU}_{\mathrm{ds}}$ takes over the surface sublimation during high wind speeds. This latent heat release cools the surface. In

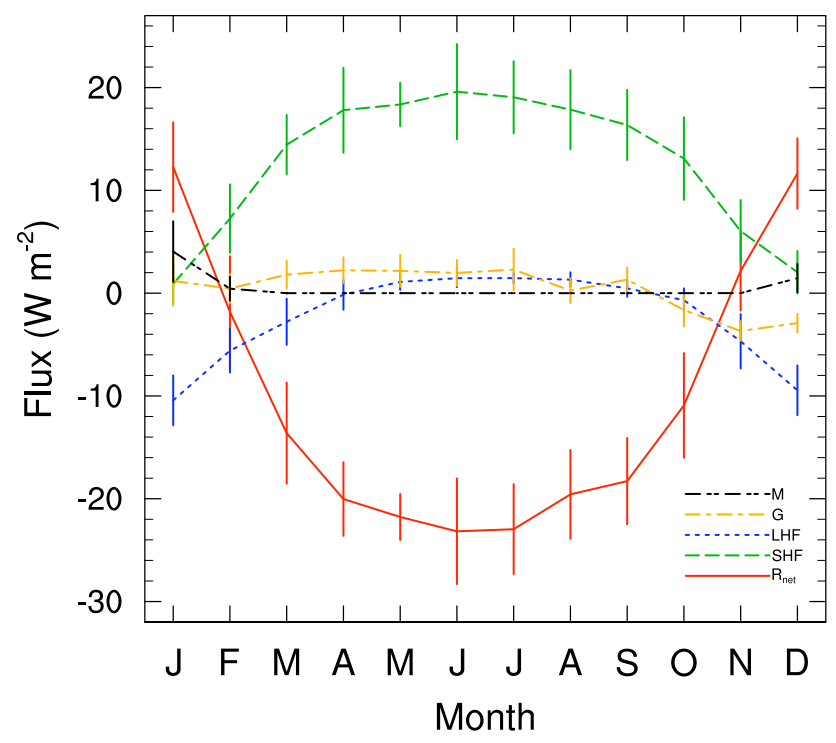

Fig. 5. Monthly mean energy balance components and their interannual variability (1993-2007) from the surface energy balance model, driven by observation, which is described by Van den Broeke et al. (2006). The error bars indicate two standard deviations from the mean. Shown are the balance of shortwave and longwave fluxes $\left(R_{\text {net }}\right)$, latent heat flux (LHF), sensible heat flux (SHF), ground heat flux $(\mathrm{G})$ and melt $(\mathrm{M})$.

order to maintain the energy balance at the surface, the sensible heat flux increases during snowdrift events (Fig. 7c).

\subsection{Horizontal snowdrift transport}

Apart from $\mathrm{SU}_{\mathrm{ds}}$, snowdrift also constitutes the horizontal transport of drifting snow, which leads to local movement of snow from wind-exposed locations towards sheltered regions (Fig. 7d). Transport divergence represents a net mass loss at the surface $\left(\nabla \cdot \mathrm{TR}_{\mathrm{ds}}\right)$. It may be highly significant at the local scale, but its contribution to the regional SMB has been assumed to be two or three orders of magnitude smaller than $\mathrm{SU}_{\mathrm{ds}}$ (Déry and Yau, 2002).

For the purpose of additional validation of the model, modelled horizontal snow transport fluxes were compared with observations from particle impact sensors (Van den Broeke et al., 2002a) during the ENABLE campaign in January and February 2002 at Kohnen base (Van As et al., 2006). The observed $10 \mathrm{~m}$ wind speed reached $16 \mathrm{~m} \mathrm{~s}^{-1}$ around 12 January before decreasing rapidly towards values between 3 and $12 \mathrm{~m} \mathrm{~s}^{-1}$ between 13 and 20 January. After this period, winds did not exceed $8 \mathrm{~m} \mathrm{~s}^{-1}$. The average $2 \mathrm{~m}$ temperature during the campaign was $244.7 \mathrm{~K}$ and the average $10 \mathrm{~m}$ wind speed $5.3 \mathrm{~m} \mathrm{~s}^{-1}$. During the measurement campaign, three snowdrift events were observed (Fig. 8). The first, strongest event yielded a horizontal transport flux of $0.07 \mathrm{~kg} \mathrm{~m}^{-1} \mathrm{~s}^{-1}$. The model overestimates the horizontal flux by a factor of two to three, but agrees on the timing of the event. The 

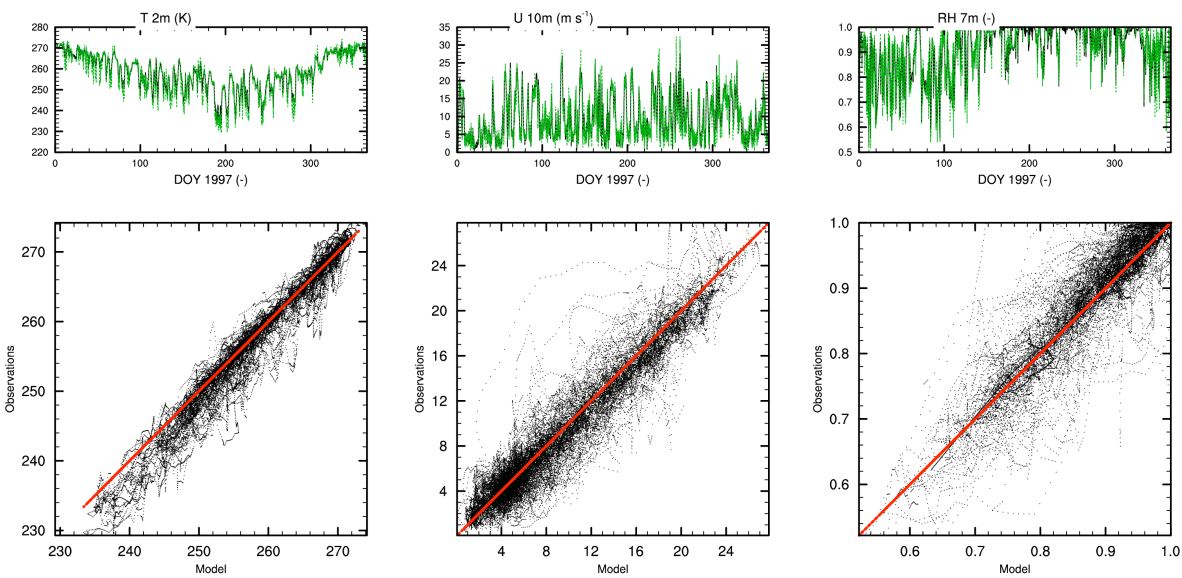

Fig. 6. Time evolution (above) and scatter plots (below) of 12-h interpolated model results vs. hourly observations of near-surface temperature (left), wind (middle) and relative humidity (right) for the year 1997 at Neumayer. Green lines represent the model results and black lines are observations. The $7 \mathrm{~m} \mathrm{RH}$ is shown because it serves as direct input for the snowdrift routine.
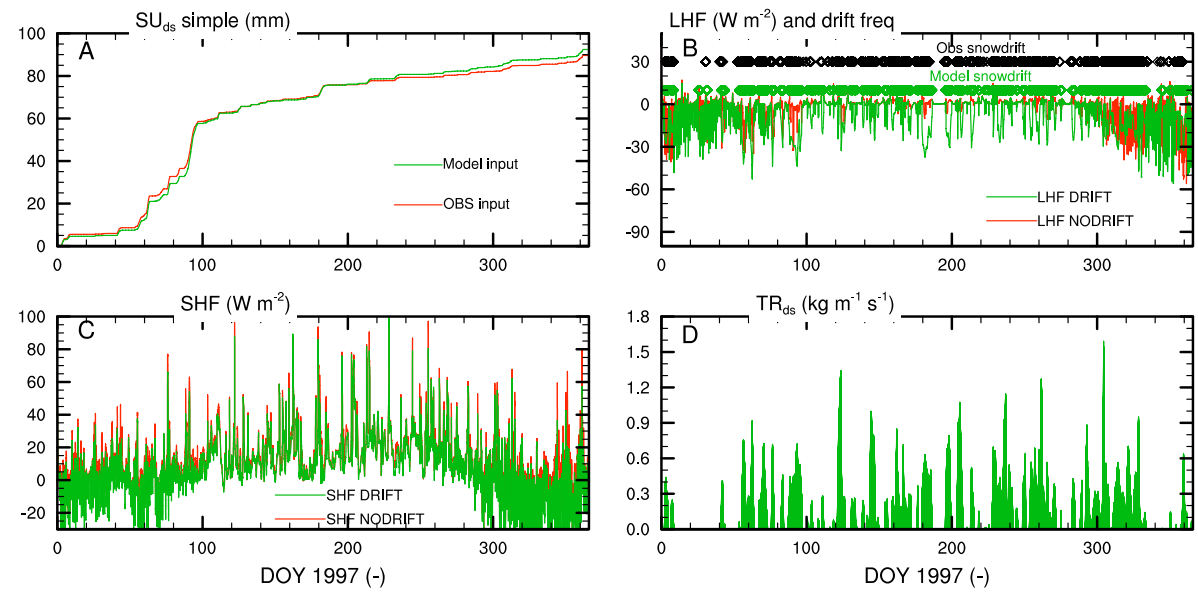

Fig. 7. Time evolution of (A): cumulative $S_{\mathrm{ds}_{\mathrm{d}}}$ derived by the simple parameterization (see text), modelled surface fluxes - (B): latent heat flux; (C): sensible heat flux, both in $\mathrm{W} \mathrm{m}^{-2}$ - and snowdrift variables - (B): timing of the snowdrift events in the observations (black) and model (green) and (D): $\mathrm{TR}_{\mathrm{ds}}$. In panel (B) and (C), the green line represents the DRIFT simulation and the red line shows the NODRIFT simulation.

second (DOY 16) and third (DOY 20) events are not detected by the model, but their intensity is observed to be very small. This overestimation of $\mathrm{TR}_{\mathrm{ds}}$ was also seen in Xiao et al. (2000), where PIEKTUK-D calculated higher transport rates compared to other models in idealized experiments. Yang and Yau (2008) compared modelled and measured particle spectra at Byrd station, and showed that the overall pattern of the distribution is well represented, but that there are discrepancies between model and measurements. Another possible reason for the overestimated transport is the assumption of a logarithmic vertical profile of wind speed, which could result in too high modelled transport rates in very stable near-surface conditions. The modelled amount of net SU and $\mathrm{SU}_{\mathrm{ds}}$ is negligible during this event, because the relative humidity was $100 \%$ (Fig. 8).
At Neumayer, horizontal transport can reach $1.6 \mathrm{~kg} \mathrm{~m}^{-1} \mathrm{~s}^{-1}$ during strong snowdrift events (Fig. 7d), which is 10 times larger than the modelled transport flux at the ENABLE site. Stronger winds, higher temperatures and more frequent snowfall cause $\mathrm{SU}_{\mathrm{ds}}$ to be much more significant in coastal Antarctica compared to the inland plateau. Although strong wind events do occur on the plateau (Van As et al., 2007), they are less severe and less frequent than the ones near the coast (Turner et al., 2009).

\subsection{Seasonal cycle}

Figure 9 presents the mean (1993-2007) seasonal cycle and its inter-annual variability, based on monthly means of $\mathrm{SU}_{\mathrm{ds}}, \mathrm{TR}_{\mathrm{ds}}$, snowdrift frequency and of $2 \mathrm{~m}$ temperature, 

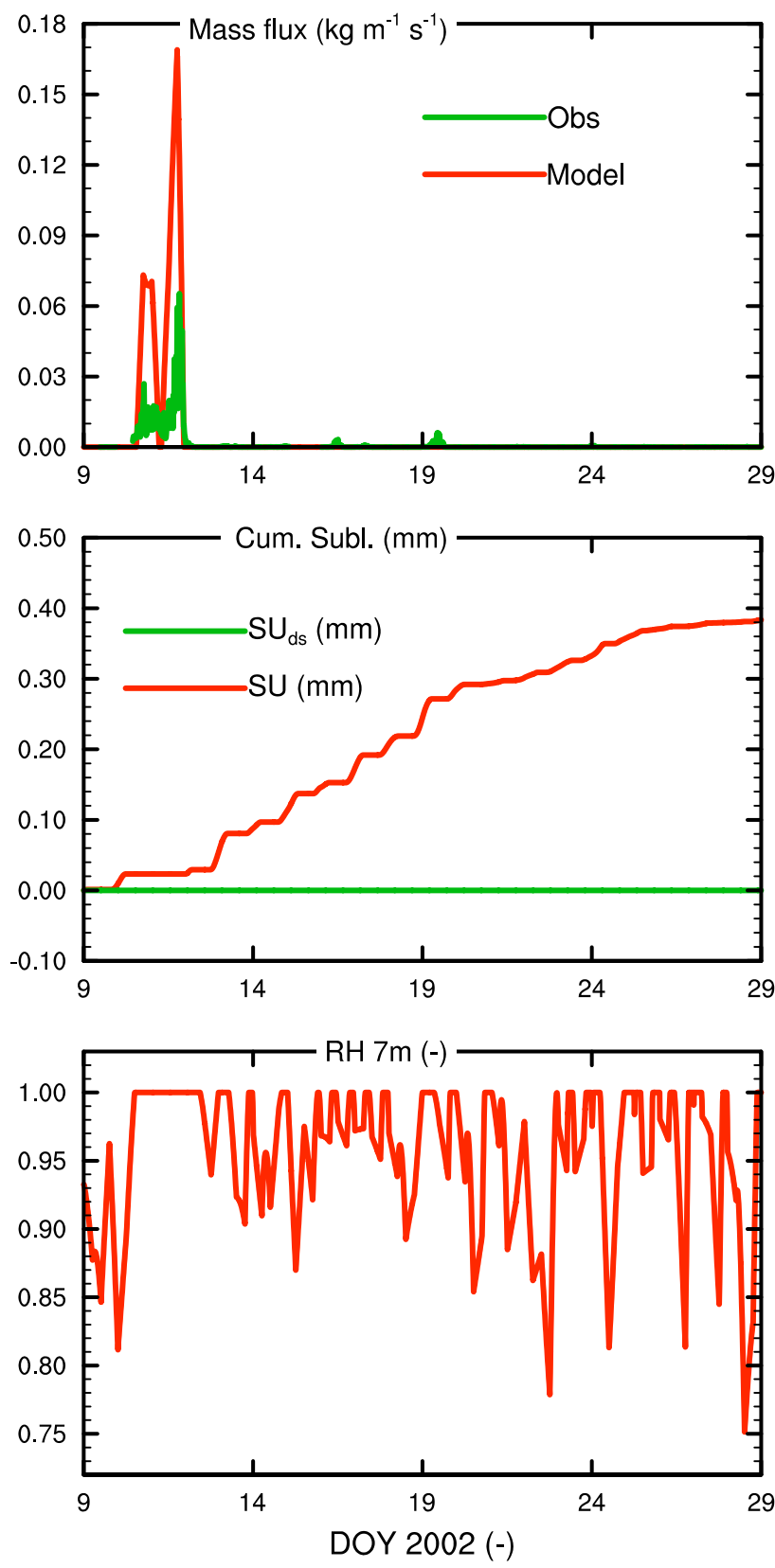

Fig. 8. Time evolution of the snow drift fluxes at Kohnen during the first part of the EPICA-ENABLE campaign, from 9 January until 29 January 2002. The upper panel shows $\mathrm{TR}_{\mathrm{ds}}$, the panel below gives cumulative $\mathrm{SU}_{\mathrm{ds}}$, together with surface sublimation (SU). The green line in the upper panel gives the observed mass fluxes, the red line shows the model results. After this period no snowdrift events were observed or modelled.

$10 \mathrm{~m}$ wind and $7 \mathrm{~m}$ relative humidity. $\mathrm{SU}_{\mathrm{ds}}$ varies strongly throughout the year. Minimum values of 0.1 to $0.15 \mathrm{~mm} \mathrm{~d}^{-1}$ occur in January and December. Strongest $\mathrm{SU}_{\mathrm{ds}}$ occurs between March and November, with daily amounts of 0.2 to $0.25 \mathrm{~mm}$. Inter-annual variability is larger in winter than in
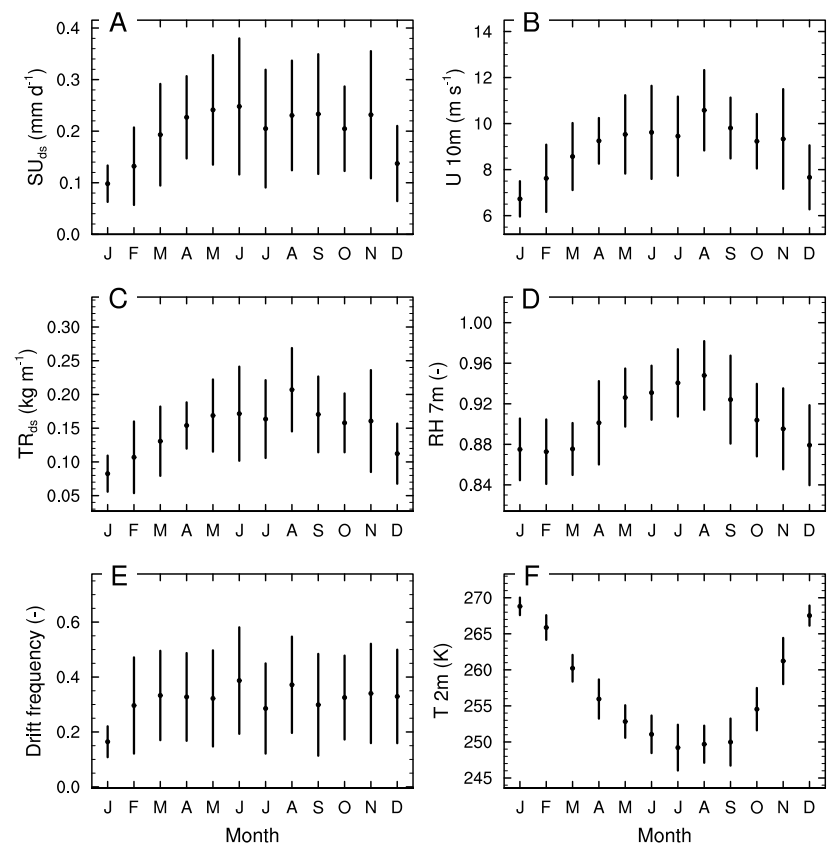

Fig. 9. 15-yr (1993-2007) monthly means (dots) and variability (the doubled standard deviation on the error bars) of $\mathrm{SU}_{\mathrm{ds}}(\mathbf{A}), \mathrm{TR}_{\mathrm{ds}}(\mathbf{C})$, snowdrift frequency (E) and the $10 \mathrm{~m}$ wind speed $(\mathbf{B}), 7 \mathrm{~m}$ relative humidity (D) and $2 \mathrm{~m}$ temperature (F).

summer. $\mathrm{SU}_{\mathrm{ds}}$ variations can be correlated with variations in the other near-surface variables. Wind speed is characterised by a strong seasonal cycle. Monthly mean $10 \mathrm{~m}$ wind speed varies between $7 \mathrm{~m} \mathrm{~s}^{-1}$ in January and more than $11 \mathrm{~m} \mathrm{~s}^{-1}$ in August. The correlation between the seasonal $\left(R^{2}=0.88\right)$ as well as the inter-annual variability $\left(R^{2}=0.72\right)$ of wind speed and $\mathrm{SU}_{\mathrm{ds}}$ is strong. However, a part of the variability is not explained by wind speed. For example, the amount of $\mathrm{SU}_{\mathrm{ds}}$ is larger in autumn (April and May) and in spring (November) than in winter (July and August), although the wind speed is clearly higher in winter. The explanation is that the relative humidity near the surface also shows a significant seasonal variability, with values ranging from $87 \%$ in summer to $96 \%$ in winter. This reduces the capacity of the air to take up moisture and consequently weakens $\mathrm{SU}_{\mathrm{ds}}$ in winter. So wind speed, relative humidity and temperature all play an important role in determining $\mathrm{SU}_{\mathrm{ds}}$. The horizontal transport is mostly related to wind speed variability $\left(R^{2}=0.99\right)$.

\subsection{Inter-annual variability}

Figure 10 shows the annual means of the key variables for the $10 \mathrm{yr}$ simulation (1993-2007) for Neumayer. Due to the high mean wind speed, snowdrift is a frequent phenomenon at Neumayer. The frequency of snowdrift varies between $33 \%$ (2004) and 49\% (1995) and is proportionally related $\left(R^{2}=0.92\right)$ to the annual mean $10 \mathrm{~m}$ wind speed. 

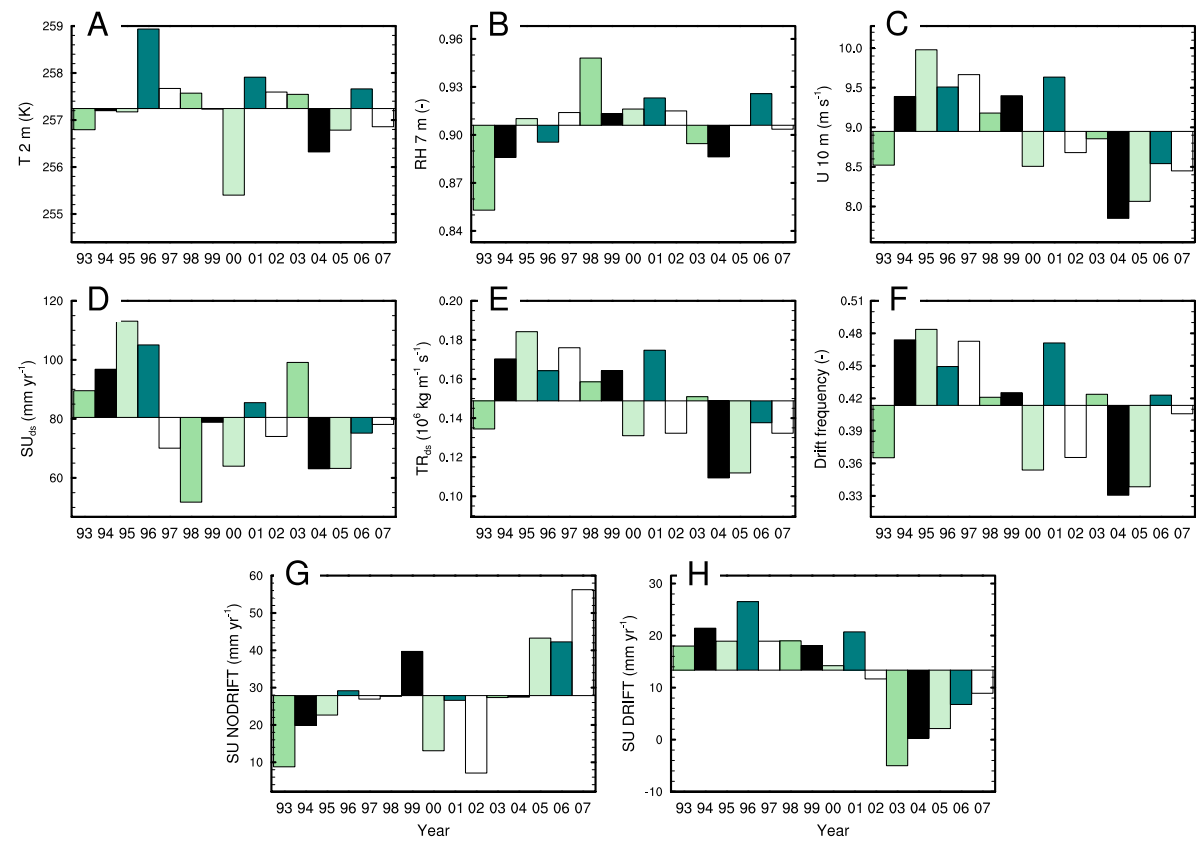

Fig. 10. Annual means (1993-2007) of $2 \mathrm{~m}$ temperature (A), $7 \mathrm{~m}$ relative humidity $(\mathbf{B}), 10 \mathrm{~m}$ wind speed $(\mathbf{C})$, snowdrift horizontal transport $(\mathbf{E})$ and snowdrift frequency $(\mathbf{F})$, combined with the cumulative amounts of snowdrift sublimation (D) and surface sublimation in the case without snowdrift $(\mathbf{G})$ and with snowdrift $(\mathbf{H})$, respectively. All variables are shown relative to their $10 \mathrm{yr}$ mean value.

The mean annual amount of snowdrift sublimation is $80 \mathrm{~mm}$. The annual cumulative amount of $\mathrm{SU}_{\mathrm{ds}}$ varies between $50 \mathrm{~mm}$ (1998) and $127 \mathrm{~mm}(1995)$ and has a standard deviation of $24 \mathrm{~mm}$. Due to the strong nonlinear nature of the snowdrift phenomenon, there is no significant correlation between annual mean values of cumulative $\mathrm{SU}_{\mathrm{ds}}$ and $2 \mathrm{~m}$ temperature, $10 \mathrm{~m}$ wind speed or $7 \mathrm{~m} \mathrm{RH}_{i}$.

Sublimation at the surface (SU) is reduced significantly when $\mathrm{SU}_{\mathrm{ds}}$ is strong due to the moistening of the surface layer (Mann et al., 2000). To analyze the feedback between $\mathrm{SU}$ and $\mathrm{SU}_{\mathrm{ds}}$, we compare the model simulations with and without snowdrift physics implemented. In the NODRIFT simulation, the cumulative net surface sublimation, defined as the sum of deposition and sublimation, varies between $7 \mathrm{~mm} \mathrm{(2002)} \mathrm{and} 56 \mathrm{~mm}$ (2007). The 15-yr annual mean surface sublimation equals $28 \mathrm{~mm}$. In the model simulation including snowdrift net SU decreases to $14 \mathrm{~mm}$ which means a reduction of $50 \%$ compared to the NODRIFT simulation. In the DRIFT simulation, surface sublimation only occurs during $7 \%$ of the time, whereas when no snowdrift is allowed, it occurs around $50 \%$ of the time.

Annual snow accumulation amounts to $425 \mathrm{~mm}$ in Neumayer (Schlosser and van Lipzig, 2002), which suggests that $\mathrm{SU}_{\mathrm{ds}}$ removes on average $16 \%$ of the precipitated snow at the surface, which is very significant. Total sublimation more than triples ( 94 versus $28 \mathrm{~mm} \mathrm{yr}^{-1}$ ) compared to the situation without snowdrift. Melt is a minor contribution to the SMB at Neumayer, because temperatures rarely reach the melting point. Snowdrift erosion is assumed to be small (Déry and
Yau, 2002). Therefore, we can estimate the annual precipitation amount at Neumayer by adding the total sublimation to the mean accumulation provided by Schlosser and van Lipzig (2002). The 15-year mean precipitation amount is then estimated to be $519 \mathrm{~mm} \mathrm{yr}^{-1}$.

\subsection{Self-limiting behaviour}

$\mathrm{SU}_{\mathrm{ds}}$ cools and moistens the near-surface air. When the air approaches saturation during winter due to high sublimation rates and low temperatures, the snowdrift sublimation process ceases. As demonstrated by Déry et al. (1998), neglecting this feedback could result in a substantial overestimation of $\mathrm{SU}_{\mathrm{ds}}$, especially during high wind speeds. In this study, the interactions are incorporated implicitly in our model, as we use near-surface observations to force the model. To investigate this further, Fig. 11 shows a strong snowdrift event at the end of February 1997, when $u_{*, t}$ is exceeded and $\mathrm{SU}_{\mathrm{ds}}$ starts during DOY 55. Wind speed increases gradually to $20 \mathrm{~m} \mathrm{~s}^{-1}$, yielding a maximum latent heat release due to snowdrift sublimation of around $70 \mathrm{~W} \mathrm{~m}^{-2}$ on DOY 56. But, due to $\mathrm{SU}_{\mathrm{ds}}$, relative humidity also increases during DOY 55 , reaching $97 \%$ on DOY 56. The high $\mathrm{RH}_{i}$ reduces the additional $\mathrm{SU}_{\mathrm{ds}}$ during DOY 57 and 58, although the wind speed remains large enough for snowdrift. At the same time, the skin temperature decreases due to $\mathrm{SU}_{\mathrm{ds}}$, increasing the sensible heat flux. This example illustrates that the feedback between the thermodynamic conditions near the surface and the snowdrift sublimation process is well captured by the model. 

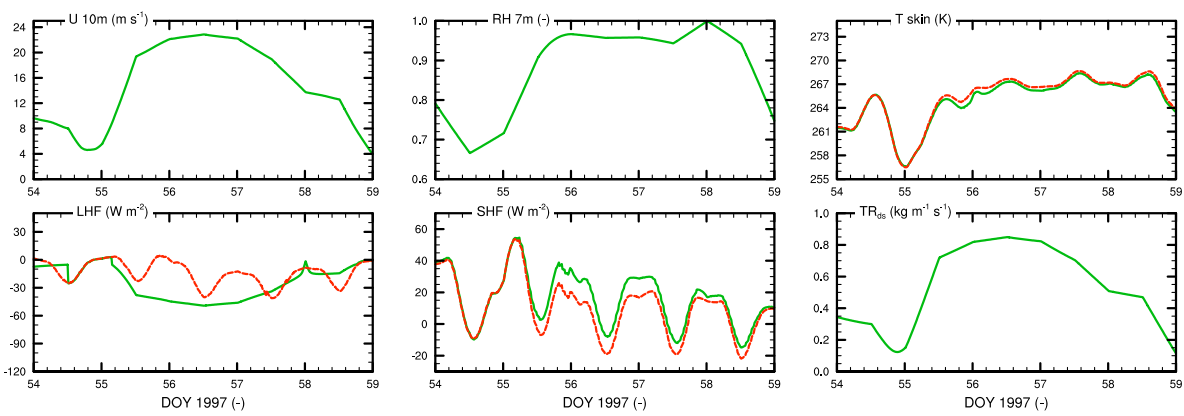

Fig. 11. Time evolution of $10 \mathrm{~m}$ wind speed, $7 \mathrm{~m}$ relative humidity, skin temperature, latent heat flux, sensible heat flux and $\mathrm{TR}_{\mathrm{ds}}$ as modelled by RACMO2-SCM, of DOY 54-59 in the year 1997 (23-28 February). The green lines represent the simulation with snowdrift, the red line is the NODRIFT simulation.

\subsection{Sensitivity to measurement errors}

The uncertainty in the measurements of the near-surface variables results in uncertainties in the modelled snowdrift sublimation amounts. To estimate these uncertainties, we have introduced systematic errors in these variables. Results from these experiments are given in Table 2 . $\mathrm{SU}_{\mathrm{ds}}$ is mainly sensitive to errors in relative humidity and temperature. These variables change the specific humidity content of the snowdrift layer, which is used for the calculation of $\mathrm{SU}_{\mathrm{ds}}$. These results also indicate that the magnitude of change in $\mathrm{SU}_{\mathrm{ds}}$ is different for a positive or negative error, which illustrates the nonlinear behaviour of this process. Errors in $u_{*, t}$ and wind speed yield still a significant, but smaller, effect on $\mathrm{SU}_{\mathrm{ds}}$.

\section{Conclusions}

The snowdrift sublimation process depends on near-surface wind speed, temperature and relative humidity. In Antarctica, the latter is generally lower at higher temperatures. $\mathrm{SU}_{\mathrm{ds}}$ shows a clear annual cycle, and is stronger in winter than in summer, which is mainly related to the annual cycle in wind speed.

In this study, we estimated that snowdrift sublimation removes around $16 \% \pm 8 \%$ of the precipitated snow at the surface at Neumayer, which is equivalent to around $80 \mathrm{~mm} \mathrm{yr}^{-1}$. This means that $\mathrm{SU}_{\mathrm{ds}}$ cannot be neglected in the $\mathrm{SMB}$ of Antarctica, especially in locations with a relatively windy, wet and mild climate. The interannual variability is significant, but the annual cumulative $\mathrm{SU}_{\mathrm{ds}}$ cannot be related to annual mean climate variables, due to the nonlinear nature of the snowdrift process. Direct observations of $\mathrm{SU}_{\mathrm{ds}}$ are not available, because no reliable method to measure snowdrift sublimation exist to date. In view of the demonstrated sensitivity of the results to near-surface data, future field campaigns should greatly improve snowdrift sublimation estimates. Additionally, direct validation data are needed, such as impact particle and sublimation sensors as well as optical particle counters to improve model estimates of snowdrift transport and sublimation. For additional evaluation,
Table 2. Sensitivity of annual accumulated $\mathrm{SU}_{\mathrm{ds}}(\%$ change compared to default value) to systematic changes of different surface variables. These adaptations are applied to $1 \mathrm{yr}$ of simulation (1997). The original $\mathrm{SU}_{\mathrm{ds}}$ amount in 1997 is $70 \mathrm{~mm}$.

\begin{tabular}{lllr}
\hline Parameter & Average & Change & Impact on $\mathrm{SU}_{\mathrm{ds}}$ \\
\hline $\mathrm{RH}_{i}$ & $91 \%$ & $+5 \%$ & $-49 \%$ \\
& & $-5 \%$ & $+63 \%$ \\
$T$ & $257.7 \mathrm{~K}$ & $+0.3 \mathrm{~K}$ & $+50 \%$ \\
& & $-0.3 \mathrm{~K}$ & $-34 \%$ \\
$u_{*, t}$ & \multirow{2}{*}{$0.3 \mathrm{~m} \mathrm{~s}^{-1}$} & $+0.05 \mathrm{~m} \mathrm{~s}^{-1}$ & $+25 \%$ \\
& & $-0.05 \mathrm{~m} \mathrm{~s}^{-1}$ & $-21 \%$ \\
$U$ & \multirow{2}{*}{$9.6 \mathrm{~m} \mathrm{~s}^{-1}$} & $+0.5 \mathrm{~m} \mathrm{~s}^{-1}$ & $+10 \%$ \\
& & $-0.5 \mathrm{~m} \mathrm{~s}^{-1}$ & $-9 \%$ \\
\hline
\end{tabular}

we compared observed and modelled horizontal transport fluxes at Kohnen on the Antarctic Plateau. Modelled fluxes are smaller than the observed fluxes, but the timing is good, which gives some confidence in a realistic representation of the snowdrift variables by the model.

The technique presented in this paper is not only applicable to regions where radiosonde measurements are available: the input for the snowdrift routine can also come from a 3-D meteorological model or reanalysis data, although this will introduce an additional uncertainty and does not allow feedbacks into the model. In the future, high-resolution 3$\mathrm{D}$ modelling of the surface mass balance of the Antarctic ice sheet including snowdrift will lead to more detailed information about the spatial variation of $\mathrm{SU}_{\mathrm{ds}}$ in Antarctica. Direct feedback between snowdrift sublimation and the atmosphere will be considered. Further work will also include a dynamic surface snow density evolution to explicitly calculate the feedback between snowdrift and the surface snow structure. However, this will only be useful when more detailed observations of surface snow density and $u_{*, t}$ become available. Based on the results presented here, we expect that snowdrift sublimation is a significant component of the SMB in the coastal regions of the Antarctic ice sheet. 
Acknowledgements. Stephen J. Déry acknowledges support from the Natural Sciences and Engineering Research Council and the Research Chair Program of Canada. We thank Andy Clifton, Richard Essery and an anonymous reviewer for their constructive comments.

Edited by: E. Hanna

\section{References}

Anderson, P.: A Method for Rescaling Humidity Sensors at Temperatures Well Below Freezing, J. Atmos. Ocean. Tech., 11, 1388-1391, 1994.

Andreas, E.: A theory for the scalar roughness and the scalar transfer coefficients over snow and sea ice, Bound.-Lay. Meteorol., 38, 159-184, 1987.

Bintanja, R.: The contribution of snowdrift sublimation to the surface mass balance of Antarctica, Ann. Glaciol., 27, 251-259, 1998.

Bintanja, R.: Snowdrift suspension and atmospheric turbulence, Part 2: Results of model simulations, Bound.-Lay. Meteorol., 95, 369-395, 2000.

Bintanja, R.: Snowdrift sublimation in a katabatic wind region of the Antarctic ice sheet, J. Appl. Meteorol., 40, 1952-1966, 2001a.

Bintanja, R.: Modelling snowdrift sublimation and its effect on the moisture budget of the atmospheric boundary layer, Tellus A, 53, 215-232, 2001b.

Bintanja, R. and Reijmer, C.: A simple parameterization for snowdrift sublimation over Antarctic snow surfaces, J. Geophys. Res., 106, 31739-31748, 2001.

Box, J., Bromwich, D., Veenhuis, B., Bai, L.-S., Stroeve, J., Rogers, J., Steffen, K., Haran, T., and Wang, S.-H.: Greenland Ice Sheet Surface Mass Balance Variability (1988-2004) from Calibrated Polar MM5 Output, J. Climate, 19, 2783-2800, 2006.

Budd, W.: The drifting of non-uniform snow particles, Studies in Antarctic Meteorology, 1966.

Déry, S. J. and Yau, M. K.: A bulk blowing snow model, Bound.Lay. Meteorol., 93, 237-251, 1999.

Déry, S. J. and Yau, M. K.: Simulation of blowing snow in the Canadian Arctic using a double-moment model, Bound.-Lay. Meteorol., 99, 297-316, 2001.

Déry, S. J. and Yau, M. K.: Large-scale mass balance effects of blowing snow and surface sublimation, J. Geophys. Res., 107, 4679, doi:10.1029/2001JD001251, 2002.

Déry, S. J., Taylor, P. A., and Xiao, J. B.: The thermodynamic effects of sublimating, blowing snow in the atmospheric boundary layer, Bound.-Lay. Meteorol., 89, 251-283, 1998.

Ettema, J., Van den Broeke, M., Van Meijgaard, E., Van de Berg, W., Bamber, J., Box, J., and Bales, R.: Higher surface mass balance of the Greenland ice sheet revealed by high-resolution climate modeling, Geophys. Res. Lett., 36, L12501,, doi:10.1029/ 2009GL038110, 2009.

Frezzotti, M., Pourchet, M., Flora, O., Gandolfi, S., Gay, M., Urbini, S., Vincent, C., Becagli, S., Gragnani, R., Proposito, M., Severi, M., Traversi, R., Udisti, R., and Fily, M.: New Estimations of Precipitation and Surface Sublimation in East Antarctica from Snow Accumulation Measurements, Clim. Dynam., 23, 803-813, 2004.
Gallée, H., Guyomarch, G., and Brun, E.: Impact of Snow Drift on the Antarctic Ice Sheet Surface Mass Balance: Possible Sensitivity to Snow-Surface Properties, Bound.-Lay. Meteorol., 99, 1-19, 2001.

Giovinetto, M. B., Bromwich, D. H., and Wendler, G.: Atmospheric net transport of water vapor and latent heat across 70 degrees $\mathrm{S}$, J. Geophys. Res., 97, 917-930, 1992.

Hyland, R. W. and Wexler, A.: Formulations for the Thermodynamic Properties of the saturated Phases of $\mathrm{H}_{2} \mathrm{O}$ from $173.15 \mathrm{~K}$ to $473.15 \mathrm{~K}$, American Society of Heating, Refrigerating, and Air-Conditioning Engineers Trans, 89, 500-519, 1984.

King, J., Anderson, P., Smith, M., and Mobbs, S.: The Surface Energy and Mass Balance at Halley, Antarctica during winter, J. Geophys. Res., 101, 19119-19128, 1996.

König, G.: Roughness length of an Antarctic ice shelf, Polarforschung, 55, 27-32, 1985.

König-Langlo, G., King, J., and Pettre, P.: Climatology of the Three Coastal Antarctic Stations Dumont d'Urville, Neumayer, and Halley, J. Geophys. Res., 103, 10935-10946, 1998.

König-Langlo, G. C. and Loose, B.: The meteorological observatory at Neumayer stations (GvN and NM-II), Antarctica, Polarforschung, 76, 25-38, 2007.

Mann, G., Anderson, P., and Mobbs, S.: Profile measurements of blowing snow at Halley, Antarctica, J. Geophys. Res., 105, 24491-24508, 2000.

Pomeroy, J. and Essery, R.: Turbulent fluxes during blowing snow: field tests of model sublimation predictions, Hydrol. Process., 13, 2963-2975, 1999.

Rignot, E., Bamber, J. L., van den Broeke, M. R., Davis, C., Li, Y., van de Berg, W. J., and van Meijgaard, E.: Recent Antarctic ice mass loss from radar interferometry and regional climate modelling, Nat. Geosci., 1, 106-110, 2008.

Schlosser, E.: Effects of Seasonal Variability of Accumulation on Yearly Mean $\delta^{18} \mathrm{O}$ Values in Antarctic Snow, J. Glaciol., 45, 463-468, 1999.

Schlosser, E. and van Lipzig, N.: Temporal Variability of Accumulation at Neumayer Station, Antarctica, from Stake Array Measurements and a Regional Atmospheric Model, J. Glaciol., 48, 87-94, 2002.

Turner, J., Connelley, W. M., Leonard, S., Marshall, G. J., and Vaughan, D. G.: Spatial and Temporal Variability of Net Snow Accumulation over the Antarctic from ECMWF Re-Analysis Project Data, Int. J. Climatol., 19, 697-724, 1999.

Turner, J., Lachlan-Cope, T., Marshall, G., Morris, E., Mulvaney, R., and Winter, W.: Spatial variability of Antarctic Peninsula net surface mass balance, J. Geophys. Res., 107, 4173, doi:10.1029/ 2001JD000755, 2002.

Turner, J., Chenoli, S. N., Abu Samah, A., Marshall, G., Phillips, T., and Orr, A.: Strong wind events in the Antarctic, J. Geophys. Res., 114, D18103, doi:10.1029/2008JD011642, 2009.

Van As, D., van den Broeke, M., and Helsen, M.: Structure and dynamics of the summertime atmospheric boundary layer over the Antarctic Plateau: 1. Measurements and model validation, J. Geophys. Res., 111, D07102, doi:10.1029/2005JD005948, 2006.

Van As, D., Van den Broeke, M., and Helsen, M. M.: Strong-wind events and their impact on the near-surface climate at Kohnen Station on the Antarctic Plateau, Antarct. Sci., 19, 507-519, 2007. 
Van de Berg, W., van den Broeke, M., Reijmer, C., and van Meijgaard, E.: Characteristics of the Antarctic surface mass balance (1958-2002) using a regional atmospheric climate model, Ann. Glaciol., 41, 97-104, 2005.

Van de Berg, W., van den Broeke, M., Reijmer, C., and van Meijgaard, E.: Reassessment of the Antarctic surface mass balance using calibrated output of a regional atmospheric climate model, J. Geophys. Res., 111, D11104, doi:10.1029/2005JD006495, 2006.

Van den Broeke, M., Van As, D., Boot, W., and Snellen, H.: EPICA-Netherlands Atmospheric Boundary Layer Experiment (ENABLE), Tech. rep., IMAU, 2002a.

Van den Broeke, M., van Lipzig, N., and van Meijgaard, E.: Momentum budget of the East-Antarctic atmospheric boundary layer: results of a regional climate model, J. Atmos. Sci., 59, 3117-3129, 2002b.

Van den Broeke, M., van Lipzig, N., and van Meijgaard, E.: Factors controlling the near-surface wind field in Antarctica, Mon. Weather Rev., 131, 733-743, 2003.
Van den Broeke, M., Reijmer, C., van As, D., and Boot, W.: Daily cycle of the surface energy balance in Antarctica and the influence of clouds, Int. J. Climatol., 26, 1587-1605, 2006.

Van den Broeke, M., König-Langlo, G., Picard, G., Kuipers Munneke, P., and Lenaerts, J.: Surface energy balance, melt and sublimation at Neumayer Station, East Antarctica, Antarct. Sci., 22, 87-96, 2010.

Vaughan, D., Bamber, J., Giovinetto, M., Russel, J., and Cooper, A.: Reassessment of net surface mass balance in Antarctica, J. Climate, 12, 933-946, 1999.

White, P.: Physical processes (CY23R4), Tech. rep., European Centre for Medium-Range Weather Forecasts (ECMWF), 2001.

Xiao, J. B., Bintanja, R., Dery, S. J., Mann, G. W., and Taylor, P. A.: An intercomparison among four models of blowing snow, Bound.-Lay. Meteorol., 97, 109-135, 2000.

Yang, J. and Yau, M.: A new triple-moment blowing snow model, Bound.-Lay. Meteorol., 126, 137-155, doi:10.1007/s10546-0079215-4, 2008 